\title{
Optimization of Multiple Active Ion Doped Fiber Amplifiers for Three Communication Windows
}

\author{
Chun Jiang and Li Jin \\ State Key Laboratory of Advanced Optical Communication Systems and Networks, Shanghai Jiao Tong University, \\ Shanghai 200240, China \\ Correspondence should be addressed to Chun Jiang, cjiang@sjtu.edu.cn
}

Received 19 January 2009; Accepted 13 March 2009

Recommended by Gang-Ding Peng

\begin{abstract}
We present for the first time a theoretical model of $\mathrm{Er}^{3+}-\mathrm{Tm}^{3+}-\mathrm{Pr}^{3+}$ codoped fiber pumped with both $800 \mathrm{~nm}$ and $980 \mathrm{~nm}$ lasers to explore possibility of this co-doped system as all-wave fiber amplifier. The rate and power propagation equations of the model are solved numerically and the dependence of the gains at 1310,1470,1530,1600, $1650 \mathrm{~nm}$ windows on fiber length is calculated. The results show that with pump power of $200 \mathrm{~mW} / 200 \mathrm{~mW}$, when the concentrations of $\mathrm{Pr}^{3+}, \mathrm{Tm}^{3+}, \mathrm{Er}^{3+}$ are around $1.7 \times 10^{24}$, $3.9 \times 10^{24}, 1.2 \times 10^{24}$ (ions $/ \mathrm{m}^{3}$ ), respectively, the signals at $1310,1470,1530,1600,1650 \mathrm{~nm}$ may be nearly equally amplified with gain of 13-16.0 dB in the active fiber with length of $23.5 \mathrm{~m}$; the co-doping concentrations and fiber length and pump powers may be further optimized to reduce the ripple.
\end{abstract}

Copyright ( $\odot 2009$ C. Jiang and L. Jin. This is an open access article distributed under the Creative Commons Attribution License, which permits unrestricted use, distribution, and reproduction in any medium, provided the original work is properly cited.

\section{Introduction}

All-wave fiber in which $\mathrm{OH}$ group was suppressed is attracting increasing interest in optical transmission system and network because it has low loss windows of $400 \mathrm{~nm}$ covering the range $1250-1650 \mathrm{~nm}$. Wavelength Division Multiplexing (WDM) has been the most important technology of large capacity optical transmission system, and optical amplifiers are the key devices of WDM system. Although Fiber Raman Amplifier (FRA) is a promising candidate for long haul and large capacity transmission system, it requires high pump power due to its lower pump efficiency; thus, the solution scheme for all-wave fiber transmission system is not available yet. Compared to FRA, rare-earth doped fiber amplifier has high gain and high pump efficiency, and in the past decade, the research on the rare-earth doped fiber amplifier has been focusing on the single-rare earthdoped fiber amplifiers, and all the amplifiers have their own bandwidths. $\mathrm{Er}^{3+}$-doped fiber amplifier (EDFA) with new split-band configuration $[1,2]$ was reported providing gain bandwidth of more than $100 \mathrm{~nm}$ covering the range 1500 $1600 \mathrm{~nm} ; \mathrm{Tm}^{3+}$-doped fiber amplifiers (TDFAs) [3-5] and $\mathrm{Pr}^{3+}$-doped fiber amplifiers (PDFA) [6] separately provided amplification in range of $1450-1520 \mathrm{~nm}$ and $1280-1340 \mathrm{~nm}$, respectively.

Recent research on emission properties of $\mathrm{Er}^{3+}-\mathrm{Tm}^{3+} \mathrm{CO}-$ doped and $\mathrm{Pr}^{3+}-\mathrm{Er}^{3+}$ co-doped fibers showed that the combination of the emission at $1530 \mathrm{~nm}$ window due to $\mathrm{Er}^{3+}:{ }^{4} \mathrm{I}_{13 / 2} \rightarrow{ }^{4} \mathrm{I}_{15 / 2}$ transition with the emission at $1470 \mathrm{~nm}$ window due to $\mathrm{Tm}^{3+}:{ }^{3} \mathrm{H}_{4}-{ }^{3} \mathrm{~F}_{4}$ transition may generate a larger seamless emission spectrum up to $200 \mathrm{~nm}$ in the codoped system [7-12]. Meanwhile, the research on emission properties of $\mathrm{Pr}^{3+}-\mathrm{Er}^{3+}$ co-doped fiber showed that the combination of the emission at $1530 \mathrm{~nm}$ window due to $\mathrm{Er}^{3+}: \mathrm{I}_{13 / 2} \rightarrow{ }^{4} \mathrm{I}_{15 / 2}$ transition with the emission at $1310 \mathrm{~nm}$ window due to $\mathrm{Pr}^{3+}:{ }^{3} \mathrm{~F}_{4}-{ }^{3} \mathrm{H}_{5}$ transition may generate an emission spectrum having two peaks centered at $1310 \mathrm{~nm}$ and $1530 \mathrm{~nm}$ windows [7-13]. In this article, we present a theoretical model of $\mathrm{Er}^{3+}-\mathrm{Tm}^{3+}-\mathrm{Pr}^{3+}$ co-doped fiber amplifier for the first time to explore the possibility of this multiple rare-earth doped system for all-wave fiber transmission system application. After the rate and power propagation equations of the doped system are solved numerically and analyzed, the parameters of doped fiber are optimized to achieve the equalized gains for 1310, 1470, 1530, 1600, $1650 \mathrm{~nm}$ bands. 


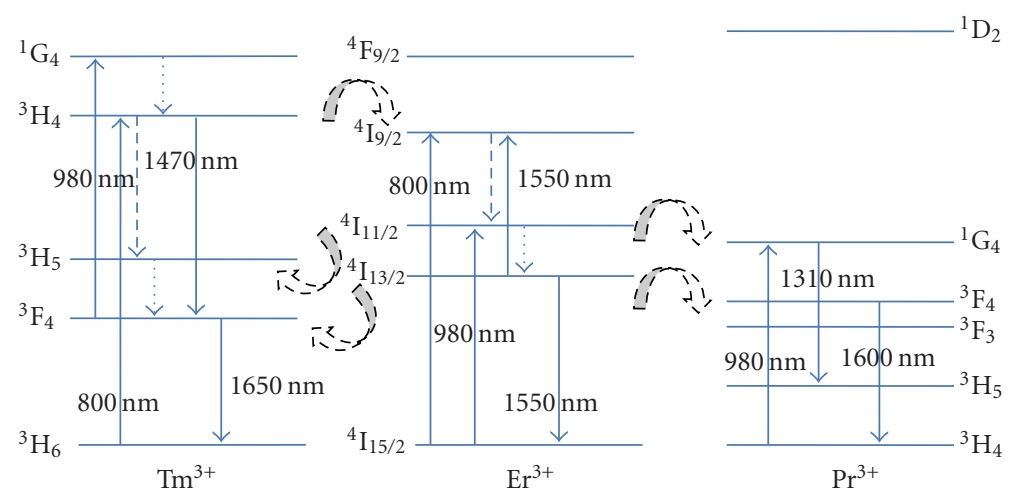

FIGURE 1: Schematic of energy levels and transition configurations of $\mathrm{Er}^{3+}-\mathrm{Tm}^{3+}-\mathrm{Pr}^{3+}$ co-doped telluride fiber amplifier pumped with both $800 \mathrm{~nm}$ and $980 \mathrm{~nm}$ laser diodes.

\section{Theoretical Model}

Figure 1 shows the schematic of the energy levels and electron transitions and energy transfer process of $\mathrm{Er}^{3+}$ $\mathrm{Tm}^{3+}-\mathrm{Pr}^{3+}$-co-doped system pumped by both $800 \mathrm{~nm}$ and $980 \mathrm{~nm}$ lasers. Following the diagram, the rate equations can be written as an equation group:

$$
\begin{aligned}
& \frac{\partial N_{1}}{\partial t}=-\left(W_{13}+W_{14}\right) N_{1}+A_{21} N_{2}+\left(W_{31}+A_{31}\right) N_{3} \\
& +\left(W_{41}+A_{41}\right) N_{4}-W_{\mathrm{ET} 63} N_{1} N_{6}-W_{\mathrm{ET} 74} N_{1} N_{7}, \\
& \frac{\partial N_{2}}{\partial t}=-\left(W_{24}+A_{21}\right) N_{2}+\left(W_{42}+A_{42}\right) N_{4} \text {, } \\
& \frac{\partial N_{3}}{\partial t}=W_{13} N_{1}-\left(W_{31}+A_{31}\right) N_{3}+W_{\mathrm{ET} 63} N_{1} N_{6}, \\
& \frac{\partial N_{4}}{\partial t}=W_{24} N_{2}-\left(W_{41}+W_{42}+A_{41}\right) N_{4}+W_{\mathrm{ET} 74} N_{1} N_{7}, \\
& \frac{\partial N_{5}}{\partial t}=-\left(W_{57}+W_{58}\right) N_{5}+W_{68} N_{6}^{2}+W_{\mathrm{ET} 63} N_{1} N_{6} \\
& +W_{\mathrm{ET} 74} N_{1} N_{7}+\left(W_{65}+A_{65}\right) N_{6}+W_{\mathrm{ET} 6-10} N_{6} N_{9} \\
& +W_{\mathrm{ET} 7-11} N_{7} N_{9}-W_{\mathrm{ET} 12-8} N_{5} N_{12} \text {, } \\
& \frac{\partial N_{6}}{\partial t}=-W_{\mathrm{ET} 63} N_{1} N_{6}-\left(W_{65}+A_{65}\right) N_{6} \\
& -W_{\mathrm{ET} 6-10} N_{6} N_{9}+A_{76} N_{7}-2 W_{68} N_{6}^{2} \text {, } \\
& \frac{\partial N_{7}}{\partial t}=W_{57} N_{5}+A_{87} N_{8}-\left(W_{\mathrm{ET} 74} N_{1}+A_{76}\right) N_{7} \\
& -W_{\mathrm{ET} 7-11} N_{7} N_{9} \text {, } \\
& \frac{\partial N_{8}}{\partial t}=W_{58} N_{5}-W_{\mathrm{ET} 12-8} N_{12} N_{5}-A_{87} N_{8}+W_{68} N_{6}^{2} \text {, } \\
& \frac{\partial N_{9}}{\partial t}=-\left(W_{9-12}+W_{\mathrm{ET} 6-10} N_{6}+W_{\mathrm{ET} 7-11} N_{7}\right) N_{9} \\
& +W_{\mathrm{ET} 12-8} N_{5} N_{12}+\left(W_{10-9}+A_{10-9}\right) N_{10}-W_{9-10} N_{9} \text {, } \\
& \frac{\partial N_{10}}{\partial t}=-\left(W_{10-9}+A_{10-9}\right) N_{10}+W_{9-10} N_{9}+W_{\text {ET6-10 }} N_{6} N_{9} \\
& +A_{11-10} N_{11}+\left(W_{12-10}+A_{12-10}\right) N_{12} \\
& -W_{10-12} N_{10}-W_{10-13} N_{10} \text {, }
\end{aligned}
$$

$$
\begin{aligned}
\frac{\partial N_{11}}{\partial t}= & W_{\mathrm{ET} 7-11} N_{7} N_{9}-A_{11-10} N_{11}+A_{12-11} N_{12} \\
\frac{\partial N_{12}}{\partial t}= & W_{9-12} N_{9}+A_{13-12} N_{13} \\
& -\left(W_{\mathrm{ET} 12-8} N_{5}+A_{12-11}+W_{12-10}\right) N_{12}+W_{10-12} N_{10} \\
\frac{\partial N_{13}}{\partial t}= & W_{10-13} N_{10}-A_{13-12} N_{13}
\end{aligned}
$$

where $N_{1}-N_{4}$ are the population densities of $\mathrm{Pr}^{3+}$ ion at energy levels ${ }^{3} \mathrm{H}_{4},{ }^{3} \mathrm{H}_{5},{ }^{3} \mathrm{~F}_{4},{ }^{1} \mathrm{G}_{4}, N_{5}-N_{8}$ are the population densities of $\mathrm{Er}^{3+}$ ion at energy levels ${ }^{4} \mathrm{I}_{15 / 2},{ }^{4} \mathrm{I}_{13 / 2},{ }^{4} \mathrm{I}_{11 / 2}$, and ${ }^{4} \mathrm{I}_{9 / 2}, N_{9}-N_{13}$ are the population densities of $\mathrm{Tm}^{3+}$ ions at energy levels ${ }^{3} \mathrm{H}_{6},{ }^{3} \mathrm{~F}_{4},{ }^{3} \mathrm{H}_{5},{ }^{4} \mathrm{H}_{4},{ }^{1} \mathrm{G}_{4} . W_{13}, W_{31}, A_{31}$ are the stimulated absorption and emission rates, spontaneous emission rate between ${ }^{3} \mathrm{H}_{4}$ and ${ }^{3} \mathrm{~F}_{4}$ levels of $\mathrm{Pr}^{3+}$, respectively. $W_{24}, W_{42}, A_{42}$ are the stimulated absorption and emission rates, spontaneous emission rate between the ${ }^{3} \mathrm{H}_{5}$ and ${ }^{1} \mathrm{G}_{4}$ levels of $\mathrm{Pr}^{3+}$, respectively. $A_{21}$ is the spontaneous emission rate between the ${ }^{3} \mathrm{H}_{4}$ and ${ }^{3} \mathrm{H}_{5}$ levels of $\mathrm{Pr}^{3+} . W_{56}, W_{65}$, $A_{65}$ are the stimulated absorption and emission rates, spontaneous emission rate between the ${ }^{4} \mathrm{I}_{15 / 2}$ and ${ }^{4} \mathrm{I}_{13 / 2}$ levels of $\mathrm{Er}^{3+}$, respectively. $W_{58}, A_{87}, A_{76}$ are the $800 \mathrm{~nm}$ pump absorption rate, spontaneous emission rate from ${ }^{4} \mathrm{I}_{9 / 2}$ to ${ }^{4} \mathrm{I}_{11 / 2}$ levels, spontaneous emission rate from ${ }^{4} \mathrm{I}_{11 / 2}$ to ${ }^{4} \mathrm{I}_{13 / 2}$ levels of $\mathrm{Er}^{3+}$, respectively. $W_{10-12}, W_{12-10}, A_{12-10}$ are the stimulated absorption and emission rates, spontaneous emission rate between the ${ }^{3} \mathrm{H}_{4}$ and ${ }^{3} \mathrm{~F}_{4}$ levels of $\mathrm{Tm}^{3+}$, respectively. $W_{9-12}, W_{9-10}, W_{10-9}, A_{10-9}, A_{12-11}, A_{11-10}$ are the $800 \mathrm{~nm}$ pump absorption rate, stimulated absorption rate, stimulated emission rate, spontaneous emission rate between ${ }^{3} \mathrm{H}_{6}$ and ${ }^{3} \mathrm{~F}_{4}$ levels of $\mathrm{Tm}^{3+}$, nonradiation transition rate from ${ }^{3} \mathrm{H}_{4}$ to ${ }^{3} \mathrm{H}_{5}$, nonradiation transition rate from ${ }^{3} \mathrm{H}_{5}$ to ${ }^{3} \mathrm{~F}_{4}$, respectively. $W_{1-4}, W_{5-8}, W_{10-13}$ are $980 \mathrm{~nm}$ pump absorption rates between the ${ }^{3} \mathrm{H}_{4}$ and ${ }^{1} \mathrm{G}_{4}$ levels of $\mathrm{Pr}^{3+}$, between the ${ }^{4} \mathrm{I}_{15 / 2}$ and ${ }^{4} \mathrm{I}_{19 / 2}$ levels of $\mathrm{Er}^{3+}$, and between the ${ }^{3} \mathrm{H}_{6}$ and ${ }^{3} \mathrm{H}_{4}$ levels of $\mathrm{Tm}^{3+}$, respectively. $W_{\mathrm{ET} 6-3}, W_{\text {ET7-4}}$, $W_{\mathrm{ET} 6-10}, W_{\mathrm{ET} 7-11}, W_{\mathrm{ET} 12-8}$ stand for the transfer rates from $\mathrm{Er}^{3+} .{ }^{4} \mathrm{I}_{13 / 2}, \mathrm{Pr}^{3+} .{ }^{3} \mathrm{H}_{4}$ to $\mathrm{Er}^{3+}:{ }^{4} \mathrm{I}_{15 / 2}, \mathrm{Pr}^{3+} .{ }^{3} \mathrm{~F}_{4}$, from $\mathrm{Er}^{3+}:{ }^{4} \mathrm{I}_{11 / 2}$, $\operatorname{Pr}^{3+}:{ }^{3} \mathrm{~F}_{4}$ to $\mathrm{Er}^{3+}:{ }^{4} \mathrm{I}_{15 / 2}, \mathrm{Pr}^{3+}:{ }^{1} \mathrm{G}_{4}$, from $\mathrm{Er}^{3+}:{ }^{4} \mathrm{I}_{11 / 2}, \mathrm{Tm}^{3+}:{ }^{3} \mathrm{H}_{6}$ to $\mathrm{Er}^{3+}:{ }^{4} \mathrm{I}_{15 / 2}, \quad \mathrm{Tm}^{3+}:{ }^{3} \mathrm{H}_{5}, \quad$ from $\quad \mathrm{Er}^{3+}:{ }^{4} \mathrm{I}_{13 / 2}, \quad \mathrm{Tm}^{3+}:{ }^{3} \mathrm{H}_{6}$ 
to $\mathrm{Er}^{3+}:{ }^{4} \mathrm{I}_{15 / 2}, \mathrm{Tm}^{3+}:{ }^{3} \mathrm{~F}_{4}$, from $\mathrm{Tm}^{3+} \cdot{ }^{3} \mathrm{H}_{4}, \mathrm{Er}^{3+}:{ }^{4} \mathrm{I}_{15 / 2}$ to $\mathrm{Tm}^{3+} \cdot{ }^{3} \mathrm{H}_{6}$, and from $\mathrm{Er}^{3+}:{ }^{4} \mathrm{I}_{9 / 2}, \mathrm{Tm}^{3+}:{ }^{3} \mathrm{H}_{6}$ to $\mathrm{Er}^{3+}:{ }^{4} \mathrm{I}_{15 / 2}$, $\mathrm{Tm}^{3+}:{ }^{3} \mathrm{~F}_{4}$, respectively. The transition rates:

$$
W_{i j}=\frac{\sigma_{i j} P_{k}}{h \nu_{k} A_{\text {eff }}} \quad(i, j=1 \sim 12, k=s, p),
$$

where $\sigma_{i j}$ is cross-section of the transition between $i$ and $j$ level, and $A_{\text {eff }}$ is the effective cross-section area. Propagation of the pump and signal and ASE power along the fiber is described by the differential equation group:

$$
\begin{aligned}
& \frac{d P_{S 1}}{d z}=\Gamma_{1310}\left(N_{3} \sigma_{\mathrm{prse} B}-N_{2} \sigma_{\mathrm{prsaB}}\right) P_{S 1}-\alpha_{1310} P_{S 1}, \\
& \frac{d P_{S 2}}{d z}=\Gamma_{1470}\left(N_{12} \sigma_{\mathrm{tmseA}}-N_{11} \sigma_{\mathrm{tmsaA}}\right) P_{S 2}-\alpha_{1470} P_{S 2}, \\
& \frac{d P_{S 3}}{d z}=\Gamma_{1550}\left(N_{6} \sigma_{\text {erse }}-N_{5} \sigma_{\text {ersaA }}-N_{8} \sigma_{\text {ersaB }}\right) P_{S 3}-\alpha_{1550} P_{S 3}, \\
& \frac{d P_{S 4}}{d z}=\Gamma_{1600}\left(N_{3} \sigma_{\mathrm{prseA}}-N_{1} \sigma_{\mathrm{prsaA}}\right) P_{S 4}-\alpha_{1600} P_{S 4}, \\
& \frac{d P_{S 5}}{d z}=\Gamma_{1650}\left(N_{10} \sigma_{\mathrm{tmse} B}-N_{9} \sigma_{\mathrm{tmsaB}}\right) P_{S 5}-\alpha_{1650} P_{S 5}, \\
& \frac{d P p_{1}}{d z}=-\Gamma_{800}\left[\left(N_{5} \sigma_{\text {erpa }}-N_{8} \sigma_{\text {erpe }}\right)\right. \\
& \left.+\left(N_{9} \sigma_{\text {tmpa }}-N_{12} \sigma_{\text {tmpe }}\right)\right] P p_{1}-\alpha_{800} P p_{1}, \\
& \frac{d P p_{2}}{d z}=-\Gamma_{980}\left[\left(N_{1} \sigma_{\text {prpa }}-N_{4} \sigma_{\text {prpe }}\right)+\left(N_{5} \sigma_{\text {erpa }}-N_{7} \sigma_{\text {erpe }}\right)\right. \\
& \left.+\left(N_{10} \sigma_{\text {tmpa }}-N_{13} \sigma_{\text {tmpe }}\right)\right] P p_{2}-\alpha_{980} P p_{2}, \\
& \frac{d P_{\text {ASE1 }}}{d z}=\Gamma_{1310}\left(N_{3} \sigma_{\text {prse } B}-N_{2} \sigma_{\text {prsaB }}\right) P_{\text {ASE } 1} \\
& +2 h v \Delta v N_{3} \sigma_{\mathrm{prse} B}-\alpha_{1310} P_{\mathrm{ASEl}} \text {, } \\
& \frac{d P_{\mathrm{ASE} 2}}{d z}=\Gamma_{1470}\left(N_{12} \sigma_{\mathrm{tmse} A}-N_{11} \sigma_{\mathrm{tmsa} A}\right) P_{\mathrm{ASE} 2} \\
& +2 h v \Delta v N_{12} \sigma_{\text {tmseA }}-\alpha_{1470} P_{\mathrm{ASE} 2} \text {, } \\
& \frac{d P_{\mathrm{ASE} 3}}{d z}=\Gamma_{1550}\left(N_{6} \sigma_{\text {erse }}-N_{5} \sigma_{\text {ersaA }}-N_{8} \sigma_{\text {ersaB }}\right) P_{\text {ASE } 3} \\
& +2 h v \Delta v N_{6} \sigma_{\text {erse }}-\alpha_{1550} P_{\text {ASE3 }}, \\
& \frac{d P_{\mathrm{ASE} 4}}{d z}=\Gamma_{1600}\left(N_{3} \sigma_{\mathrm{prse} A}-N_{1} \sigma_{\mathrm{prsa} A}\right) P_{\mathrm{ASE} 4} \\
& +2 h v \Delta v N_{3} \sigma_{\text {prseA }}-\alpha_{1600} P_{\mathrm{ASE}} \text {, } \\
& \frac{d P_{\text {ASE5 }}}{d z}=\Gamma_{1650}\left(N_{10} \sigma_{\text {tmse } B}-N_{9} \sigma_{\text {tmsaB }}\right) P_{\text {ASE5 }} \\
& +2 h v \Delta v N_{10} \sigma_{\mathrm{tmseB}}-\alpha_{1650} P_{\mathrm{ASE} 5},
\end{aligned}
$$

where $P_{p 1}, P_{p 2}$ are the pump powers at $800 \mathrm{~nm}, 980 \mathrm{~nm}$, respectively. $P_{S 1}, P_{S 2}, P_{S 3}, P_{S 4}, P_{S 5}$ are the powers of the signals at $1310,1470,1530,1600$, and $1650 \mathrm{~nm}$ bands, respectively. $P_{\mathrm{ASE} 1}, P_{\mathrm{ASE} 2}, P_{\mathrm{ASE} 3}, P_{\mathrm{ASE} 4}, P_{\mathrm{ASE} 5}$ are the powers of the ASE at $1310,1470,1530,1600$, and $1650 \mathrm{~nm}$ bands, respectively. $\Gamma_{1310}, \Gamma_{1470}, \Gamma_{1530}, \Gamma_{1600}, \Gamma_{1650}$ are overlapping factors at $1310,1470,1530,1600,1650 \mathrm{~nm}$ bands, respectively, and calculated from [14], and $v$ is signal frequency. $\alpha(v)$ is the frequency dependent background loss of the active fiber.

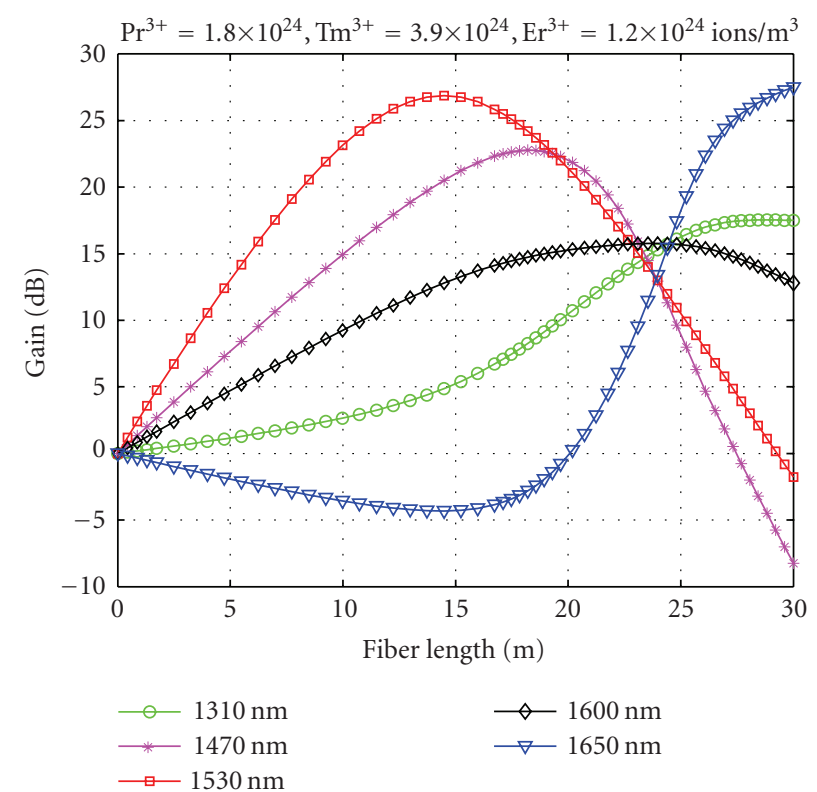

Figure 2: Variation of the gain at 1310, 1470, 1530, 1600, $1650 \mathrm{~nm}$ with fiber length. Pump power, input signal power are $200 \mathrm{~mW} / 200 \mathrm{~mW},-30 \mathrm{~dB} \mathrm{~m}$, respectively. The optimal concentration $\mathrm{Pr}^{3+}=1.9 \times 10^{24}, \mathrm{Tm}^{3+}=3.9 \times 10^{24}, \mathrm{Er}^{3+}=1.2 \times 10^{24}$ ions $/ \mathrm{m}^{3}$, and energy transfer coefficient Wet $_{6-3}=63 \times 10^{-20}$, Wet $_{6-10}=$ $200 \times 10^{-22}$

$\sigma_{\text {tmseA }}, \sigma_{\text {tmse } B}, \sigma_{\text {erse }}$ are the emission cross-sections of ${ }^{3} \mathrm{H}_{4}{ }^{-3} \mathrm{~F}_{4}$ $(1470 \mathrm{~nm})$ and ${ }^{3} \mathrm{~F}_{4}{ }^{-3} \mathrm{H}_{6}(1650 \mathrm{~nm})$ in $\mathrm{Tm}^{3+}$ ions and ${ }^{4} \mathrm{I}_{13 / 2}{ }^{-}$ ${ }^{4} \mathrm{I}_{15 / 2}(1530 \mathrm{~nm})$ in $\mathrm{Er}^{3+}$ ions, respectively. $\sigma_{\mathrm{tmsa} A}, \sigma_{\mathrm{tmsa} B}, \sigma_{\text {ersa }}$ are the absorption cross-sections of ${ }^{3} \mathrm{H}_{4}{ }^{3}{ }^{3} \mathrm{~F}_{4}(1470 \mathrm{~nm})$ and ${ }^{3} \mathrm{~F}_{4}-{ }^{3} \mathrm{H}_{6}(1650 \mathrm{~nm})$ in $\mathrm{Tm}^{3+}$ ions and ${ }^{4} \mathrm{I}_{13 / 2}{ }^{4} \mathrm{I}_{15 / 2}(1530 \mathrm{~nm})$ in $\mathrm{Er}^{3+}$ ions, respectively. $\sigma_{\mathrm{prse} A}, \sigma_{\mathrm{prsa} A}$ and $\sigma_{\mathrm{prse} B}, \sigma_{\mathrm{prsa} B}$ are the emission cross-sections of ${ }^{1} \mathrm{G}_{4}{ }^{-3} \mathrm{H}_{5}(1310 \mathrm{~nm})$ and ${ }^{3} \mathrm{~F}_{4}$ ${ }^{3} \mathrm{H}_{4}(1600 \mathrm{~nm})$ in $\mathrm{Pr}^{3+}$ ions.

The above differential equation group is solved by numerical integration along the active fiber using Newton iterative method and Runge-Kutta method. It was assumed that the energy transfer rates $\left(W_{\mathrm{ET} 63}, W_{\mathrm{ET74}}\right.$, $\left.W_{\mathrm{ET} 6-10}, W_{\mathrm{ET} 7-11}, W_{\mathrm{ET} 12-8}\right)$ were linearly increasing functions of $N_{\mathrm{Er}}^{t}, N_{\mathrm{Tm}}^{t}, N_{\mathrm{Pr}}^{t}$, respectively, $[15,16]$ and are expressed with equations:

$$
\begin{aligned}
W_{\mathrm{ET} 63}= & W_{\mathrm{ET} 74}=1.0 \times 10^{-22}+4.0 \\
& \times 10^{-49}\left[\left(N_{\mathrm{Pr}} N_{\mathrm{Er}}\right)^{1 / 2}-1.0 \times 10^{25}\right], \\
W_{\mathrm{ET} 6-10}= & W_{\mathrm{ET} 7-11}=1.0 \times 10^{-22}+4.0 \\
& \times 10^{-49}\left[\left(N_{\mathrm{Tm}} N_{\mathrm{Er}}\right)^{1 / 2}-1.0 \times 10^{25}\right], \\
W_{\mathrm{ET} 12-8}= & 1.0 \times 10^{-22}+4.0 \\
& \times 10^{-49}\left[\left(N_{\mathrm{Tm}} N_{\mathrm{Er}}\right)^{1 / 2}-1.0 \times 10^{25}\right] .
\end{aligned}
$$

\section{Result and Discussion}

Figure 2 shows the variation of the gains at the five bands $(1310,1470,1530,1600,1650 \mathrm{~nm})$ with the fiber length and with optimized dopant concentrations: $\mathrm{Pr}^{3+}$ concentration at $1.7 \times 10^{24}, \mathrm{Tm}^{3+}$ concentration at $3.9 \times 10^{24}, \mathrm{Er}^{3+}$ 
TABLE 1: Spectral parameters of $\mathrm{Er}^{3+}$-doped and $\mathrm{Tm}^{3+}$ and $\mathrm{Pr}^{3+}$ doped telluride fiber for numerical calculation.

\begin{tabular}{|c|c|c|c|c|}
\hline Parameter & Symbol & Value & Unit & Remarks \\
\hline Core diameter & $2 \mathrm{r}$ & 5.0 & $\mu \mathrm{m}$ & \\
\hline Background loss & $\alpha$ & 0.1 & $\mathrm{~dB} / \mathrm{m}$ & \\
\hline \multirow{4}{*}{$\operatorname{Pr}^{3+}$} & $\sigma_{\text {prse } B,} \sigma_{\text {prsa } B}$ & $2.0 \times 10^{-25}$ & $\mathrm{~m}^{2}$ & \multirow{4}{*}[17]{} \\
\hline & $\sigma_{\text {prseA },} \sigma_{\text {prsaA }}$ & $6.3 \times 10^{-25}$ & $\mathrm{~m}^{2}$ & \\
\hline & $A_{31}$ & 4000 & $1 / \mathrm{s}$ & \\
\hline & $A_{42}$ & 2778 & $1 / \mathrm{s}$ & \\
\hline \multirow{9}{*}{$\mathrm{Tm}^{3+}$} & $\sigma_{\text {tmseA }}$ & $4.5 \times 10^{-25}$ & $\mathrm{~m}^{2}$ & \multirow{9}{*}[18]{} \\
\hline & $\sigma_{\mathrm{tmsa} A}$ & $4.5 \times 10^{-25}$ & $\mathrm{~m}^{2}$ & \\
\hline & $\sigma_{\mathrm{tmse} B}$ & $8.6 \times 10^{-25}$ & $\mathrm{~m}^{2}$ & \\
\hline & $\sigma_{\mathrm{tmsa} B}$ & $8.6 \times 10^{-25}$ & $\mathrm{~m}^{2}$ & \\
\hline & $A_{10-9}$ & 311 & $1 / \mathrm{s}$ & \\
\hline & $A_{11-10}$ & 131 & $1 / \mathrm{s}$ & \\
\hline & $A_{10-9}$ & 400 & $1 / \mathrm{s}$ & \\
\hline & $\sigma_{\text {tmpa }}$ & $4.5 \times 10^{-25}$ & $\mathrm{~m}^{2}$ & \\
\hline & $\sigma_{\text {tmpe }}$ & $1.0 \times 10^{-27}$ & $\mathrm{~m}^{2}$ & \\
\hline \multirow{9}{*}{$\mathrm{Er}^{3+}$} & $\sigma_{\text {erse }}$ & $8.6 \times 10^{-25}$ & $\mathrm{~m}^{2}$ & \multirow{9}{*}[18]{} \\
\hline & $\sigma_{\text {ersa }}$ & $8.5 \times 10^{-25}$ & $\mathrm{~m}^{2}$ & \\
\hline & $\sigma_{\text {erpe }}$ & $1.0 \times 10^{-26}$ & $\mathrm{~m}^{2}$ & \\
\hline & $\sigma_{\text {erpa }}$ & $4.48 \times 10^{-25}$ & $\mathrm{~m}^{2}$ & \\
\hline & $\sigma_{\text {erpe }}$ & $1.0 \times 10^{-27}$ & $\mathrm{~m}^{2}$ & \\
\hline & $A_{65}$ & 172.4 & $1 / \mathrm{s}$ & \\
\hline & $A_{85}$ & 1804.3 & $1 / \mathrm{s}$ & \\
\hline & $A_{76}$ & 1000 & $1 / \mathrm{s}$ & \\
\hline & $A_{87}$ & 51000 & $1 / \mathrm{s}$ & \\
\hline \multirow{5}{*}{ Overlap factor } & \multirow{5}{*}{$\Gamma(\lambda)$} & 0.876 & & $800 \mathrm{~nm}$ \\
\hline & & 0.500 & & $1310 \mathrm{~nm}$ \\
\hline & & 0.641 & & $1470 \mathrm{~nm}$ \\
\hline & & 0.451 & & $1530 \mathrm{~nm}$ \\
\hline & & 0.300 & & $1650 \mathrm{~nm}$ \\
\hline
\end{tabular}

concentration at $1.2 \times 10^{24}$ ions $/ \mathrm{m}^{3}$ and fixed pump powers at $200 \mathrm{~mW} / 200 \mathrm{~mW}$ for $800 \mathrm{~nm} / 980 \mathrm{~nm}$.

When fiber length increases from 0.0 to $30.0 \mathrm{~m}$, the gain at $1310 \mathrm{~nm}$ increases monotonically from 0.0 to $17.6 \mathrm{~dB}$, and the gains at 1470, 1530, and $1600 \mathrm{~nm}$ increase from 0.0 to $17.7 \mathrm{~dB}, 27.0 \mathrm{~dB}, 16.0 \mathrm{~dB}$ at the fiber lengths 18.0, $14.0,23.0 \mathrm{~m}$, respectively; after these lengths, they drop. The gain at $1650 \mathrm{~nm}$ decreases from 0.0 to $-4.8 \mathrm{~dB}$; after the length $14.0 \mathrm{~m}$, it rises. We think that the variation of the gains at 1310-1600 $\mathrm{nm}$ with fiber length is reasonable. With fixed pump power and fiber length increasing from 0 to certain level, pump powers are so high that the number of population inversions between the ${ }^{1} \mathrm{G}_{4}$ and ${ }^{3} \mathrm{H}_{5}$ level of $\operatorname{Pr}^{3+}$ ions, the ${ }^{3} \mathrm{H}_{4}$ and ${ }^{3} \mathrm{~F}_{4}$ level of $\mathrm{Tm}^{3+}$ ions, the ${ }^{4} \mathrm{I}_{13 / 2}$ and ${ }^{4} \mathrm{I}_{15 / 2}$ levels of $\mathrm{Er}^{3+}$ ions increases; thus, the gains increase. When fiber length is over the level, pump powers are comsumpted so much that the inversion number drops; thereby the gain decreases. For the channel at $1650 \mathrm{~nm}$ originating from the transition from the ${ }^{3} \mathrm{~F}_{4}$ to ${ }^{3} \mathrm{H}_{6}$ levels of $\mathrm{Tm}^{3+}$, it shares same level $\left({ }^{3} \mathrm{~F}_{4}\right)$ with the channel at $1470 \mathrm{~nm}$ arising from the transition from ${ }^{3} \mathrm{H}_{4}$ and ${ }^{3} \mathrm{~F}_{4}$ level of the ions, but the shared level acts as the upper level for $1650 \mathrm{~nm}$ channel and the terminated level for $1470 \mathrm{~nm}$; therefore, the gains at $1470 \mathrm{~nm}$ and $1650 \mathrm{~nm}$ have opposite variation trend with increased fiber length.

\section{Conclusions}

In conclusion, we have presented a theoretical model of $\mathrm{Er}^{3+}-\mathrm{Tm}^{3+}-\mathrm{Pr}^{3+}$ co-doped fiber amplifier pumped with $800 \mathrm{~nm}$ and $980 \mathrm{~nm}$ lasers. The rate and power propagation equations of the model have been solved numerically and the dependence of the gains at 1310, 1470, 1530, 1600, $1650 \mathrm{~nm}$ windows on the fiber length has been calculated. The results showed that with pump power of $200 \mathrm{~mW} / 200 \mathrm{~mW}$, when concentrations of $\mathrm{Pr}^{3+}, \mathrm{Tm}^{3+}, \mathrm{Er}^{3+}$ are around $1.7 \times 10^{24}, 3.9$ $\times 10^{24}, 1.2 \times 10^{24}$ (ions $/ \mathrm{m}^{3}$ ), respectively, the signals at 1310 , $1470,1530,1600,1650 \mathrm{~nm}$ may be nearly equally amplified with gain of 13-16.0 dB in the active fiber with fiber length of $23.5 \mathrm{~m}$. The co-doping concentrations and fiber length and pump powers of the co-doped system may be further optimized to reduce the ripple. 


\section{Acknowledgments}

This work is supported by National Natural Science Foundation of China (Grants no. 60377023 and no. 60672017) and Program for New Century Excellent Talents in University and Shanghai Optical Science and Technology (no. 05DZ22009) and sponsored by Shanghai Pujiang Program.

\section{References}

[1] C.-H. Yeh, C. C. Lee, and S. Chi, "120-nm bandwidth erbium-doped fiber amplifier in parallel configuration," IEEE Photonics Technology Letters, vol. 16, no. 7, pp. 1637-1639, 2004.

[2] Y. B. Lu, P. L. Chu, A. Alphones, and P. Shum, "A 105-nm ultrawide-band gain-flattened amplifier combining C- and L-band dual-core EDFAs in a parallel configuration," IEEE Photonics Technology Letters, vol. 16, no. 7, pp. 1640-1642, 2004.

[3] E. R. M. Taylor, L. N. Ng, J. Nilsson, et al., "Thulium-doped tellurite fiber amplifier," IEEE Photonics Technology Letters, vol. 16, no. 3, pp. 777-779, 2004.

[4] R. M. Percival and J. R. Williams, "Highly efficient $1.064 \mu \mathrm{m}$ upconversion pumped $1.47 \mu \mathrm{m}$ thulium doped fluoride fibre amplifier," Electronics Letters, vol. 30, no. 20, pp. 1684-1685, 1994.

[5] T. Kasamatsu, Y. Yano, and T. Ono, "1.49- $\mu \mathrm{m}$-band gainshifted thulium-doped fiber amplifier for WDM transmission systems," Journal of Lightwave Technology, vol. 20, no. 10, pp. 1826-1838, 2002.

[6] Y. Ohishi, T. Kanamori, T. Nishi, S. Takahashi, and E. Snitzer, "Concentration effect on gain of $\mathrm{Pr}^{3+}$-doped fluoridefiber for $1.3 \mu \mathrm{m}$ amplification," IEEE Photonics Technology Letters, vol. 4, no. 12, pp. 1338-1341, 1992.

[7] H. Jeong, K. Oh, S. R. Han, and T. F. Morse, "Characterization of broadband amplified spontaneous emission from an $\mathrm{Er}^{3+}$. $\mathrm{Tm}^{3+}$ co-doped silica fiber," Chemical Physics Letters, vol. 367, no. 3-4, pp. 507-511, 2003.

[8] D. C. Yeh, R. R. Petrin, W. A. Sibley, V. Madigou, J. L. Adam, and M. J. Suscavage, "Energy transfer between $\mathrm{Er}^{3+}$ and $\mathrm{Tm}^{3+}$ ions in a barium fluoride-thorium fluoride glass," Physical Review B, vol. 39, no. 1, pp. 80-90, 1989.

[9] S. Tanabe, K. Suzuki, N. Soga, and T. Hanada, "Mechanisms and concentration dependence of $\mathrm{Tm}^{3+}$ blue and $\mathrm{Er}^{3+}$ green up-conversion in codoped glasses by red-laser pumping," Journal of Luminescence, vol. 65, no. 5, pp. 247-255, 1995.

[10] X. Zou, A. Shikida, H. Yanagita, and H. Toratani, "Mechanisms of upconversion fluorescences in $\mathrm{Er}^{3+}, \mathrm{Tm}^{3+}$ codoped fluorozircoaluminate glasses," Journal of Non-Crystalline Solids, vol. 181, no. 1-2, pp. 100-109, 1995.

[11] W. Lozano B, C. B. de Araújo, and Y. Messaddeq, "Enhanced frequency upconversion in $\mathrm{Er}^{3+}$ doped fluoroindate glass due to energy transfer from $\mathrm{Tm}^{3+}$," Journal of Non-Crystalline Solids, vol. 311, no. 3, pp. 318-322, 2002.

[12] E. Yahel and A. A. Hendy, "Modeling and optimization of short $\mathrm{Er}^{3+}-\mathrm{Yb}^{3+}$ codoped fiber lasers," IEEE Journal of Quantum Electronics, vol. 39, no. 11, pp. 1444-1451, 2003.

[13] L. Huang, A. Jha, S. Shen, and X. Liu, "Broadband emission in $\mathrm{Er}^{3+}-\mathrm{Tm}^{3+}$ codoped tellurite fibre," Optics Express, vol. 12, no. 11, pp. 2429-2434, 2004.

[14] T. J. Whitley and R. Wyatt, "Alternative Gaussian spot size polynomial for use with doped fiber amplifiers," IEEE
Photonics Technology Letters, vol. 5, no. 11, pp. 1325-1327, 1993.

[15] F. Di Pasquale and M. Federighi, "Improved gain characteristics in high-concentration $\mathrm{Er}^{3+} / \mathrm{Yb}^{3+}$ codoped glass waveguide amplifiers," IEEE Journal of Quantum Electronics, vol. 30, no. 9, pp. 2127-2131, 1994.

[16] M. Karásek, "Optimum design of $\mathrm{Er}^{3+}-\mathrm{Yb}^{3+}$ codoped fibers for large-signal high-pump-power applications," IEEE Journal of Quantum Electronics, vol. 33, no. 10, pp. 1699-1705, 1997.

[17] F. X. Gan, Optical and Spectroscopic Properties of Glass, Shanghai Science and Technology Press, Shanghai, China, 1992.

[18] S. Shen, A. Jha, X. Liu, et al., "Tellurite glasses for broadband amplifiers and integrated optics," Journal of the American Ceramic Society, vol. 85, no. 6, pp. 1391-1395, 2002. 

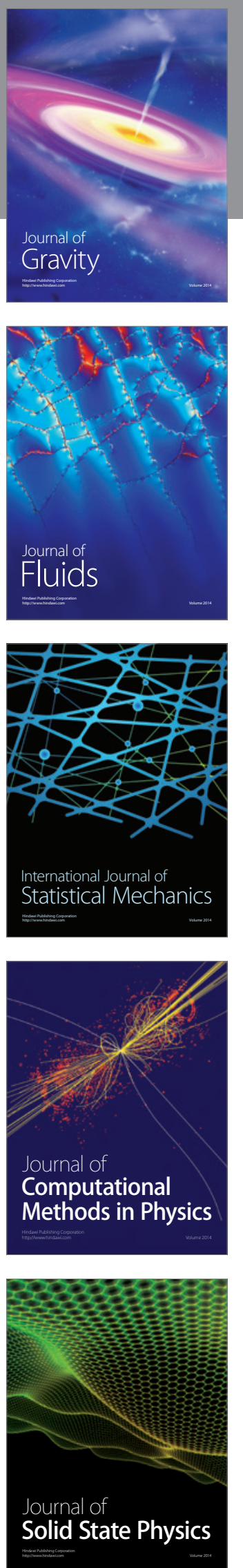

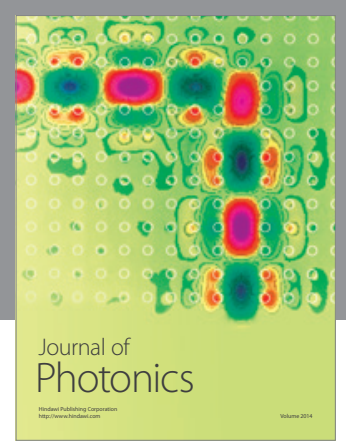

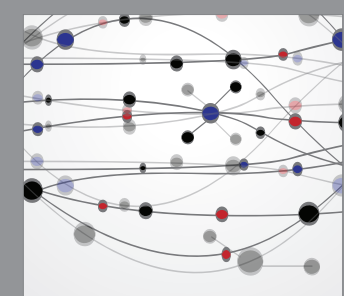

The Scientific World Journal
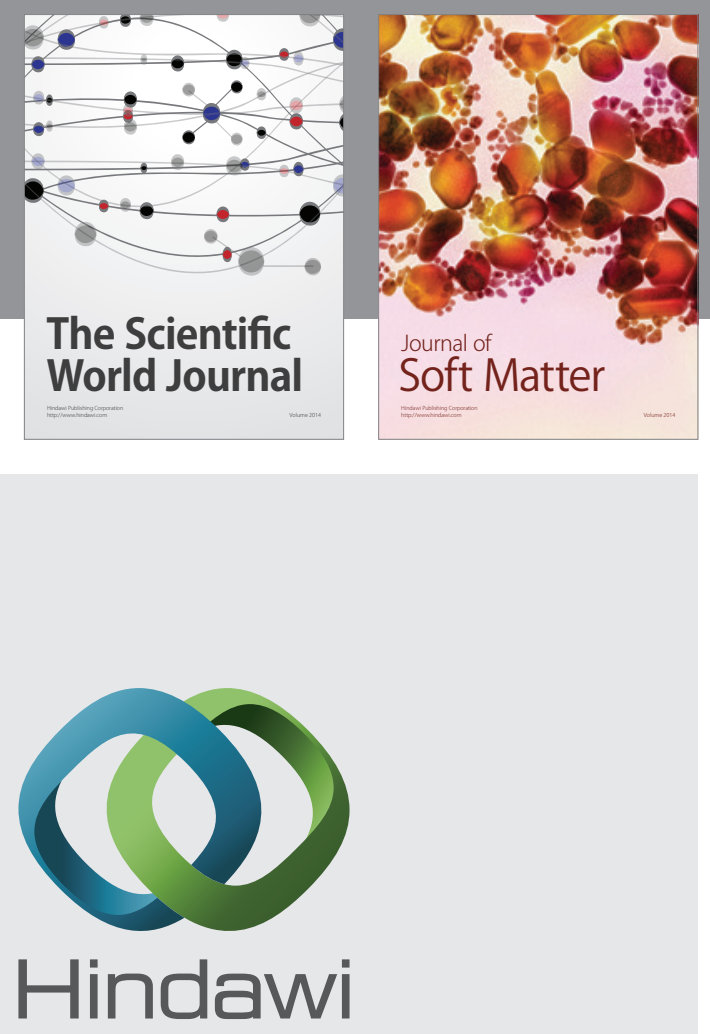

Submit your manuscripts at

http://www.hindawi.com
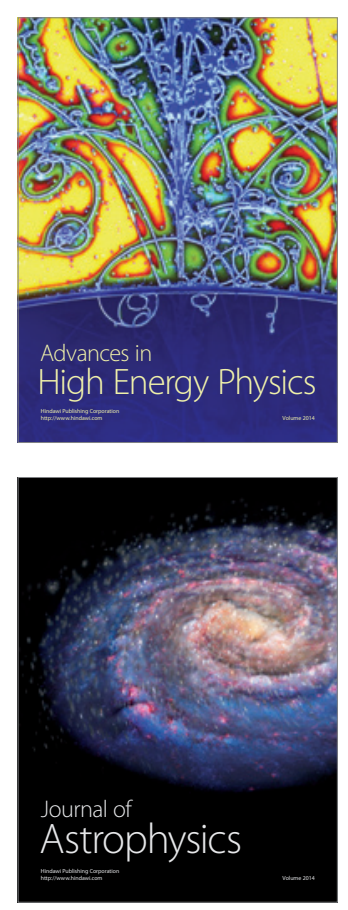
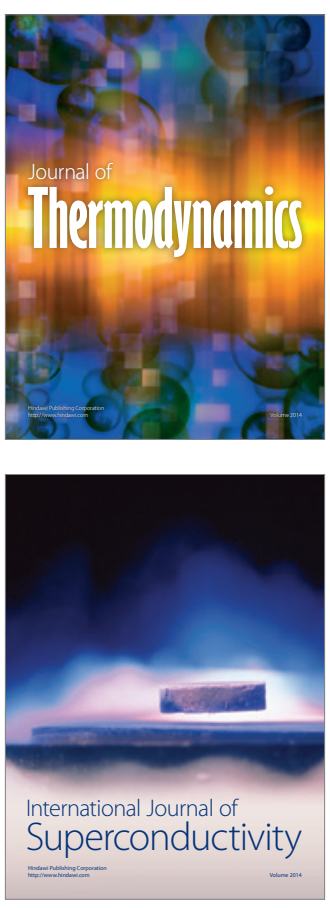
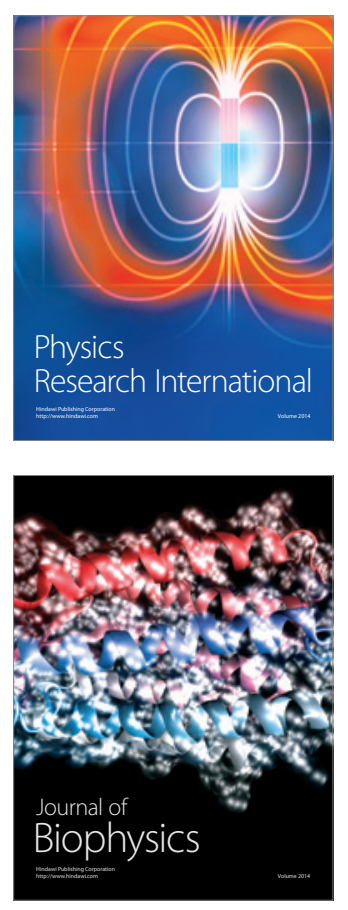
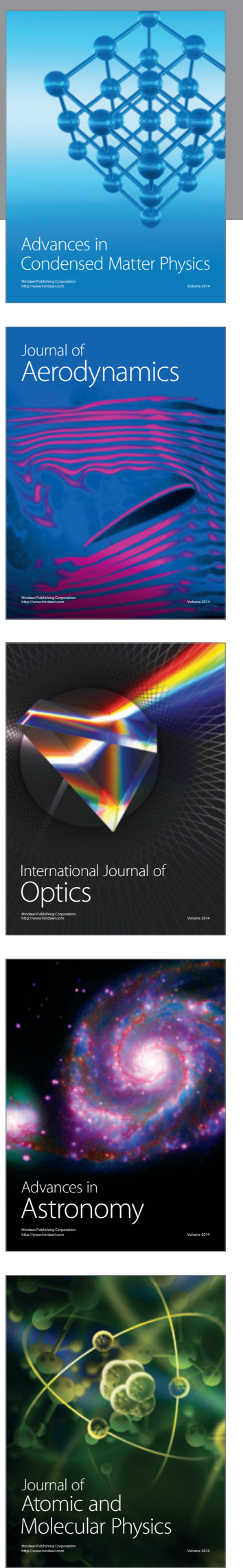